\title{
Urgent requirement for better patient selection for Short Synacthen Tests: results from a clinical audit.
}

\section{B Freudenthal, D Beder, A Ogilvie}

Watford General Hospital, West Herts Hospitals NHS Trust

Short Synacthen Tests (SST's) are commonly performed to diagnose or exclude adrenal insufficiency.

Adrenal insufficiency may present with non-specific symptoms but can be life-threatening, so a high index of suspicion is justifiable.

However, it was known that the vast majority of SST's in our hospital are 'normal'. Are these SST's always appropriate and necessary?

Why does it matter?

- Each dose of tetracosactide costs over $£ 45$ (recent $15 x$ increase)

- Outpatient tests are disruptive to patients

- Time and inconvenience of doctor/nurse performing tests

- Potential increased length of inpatient stay

- Difficulty in interpreting borderline results in asymptomatic patients

\section{Audit design:}

Every SST in our trust from a 12 month period reviewed for indication (via clinic or discharge letters), if a previous cortisol was measured, and clinical outcome.

\section{Audit demographics:}

Outpatients: 106 SST's (patient mean age 50, median age 46) Inpatients: 76 SST's (patient mean age 67, median age 74)

\section{Indication for SST \\ OUTPATIENTS:}

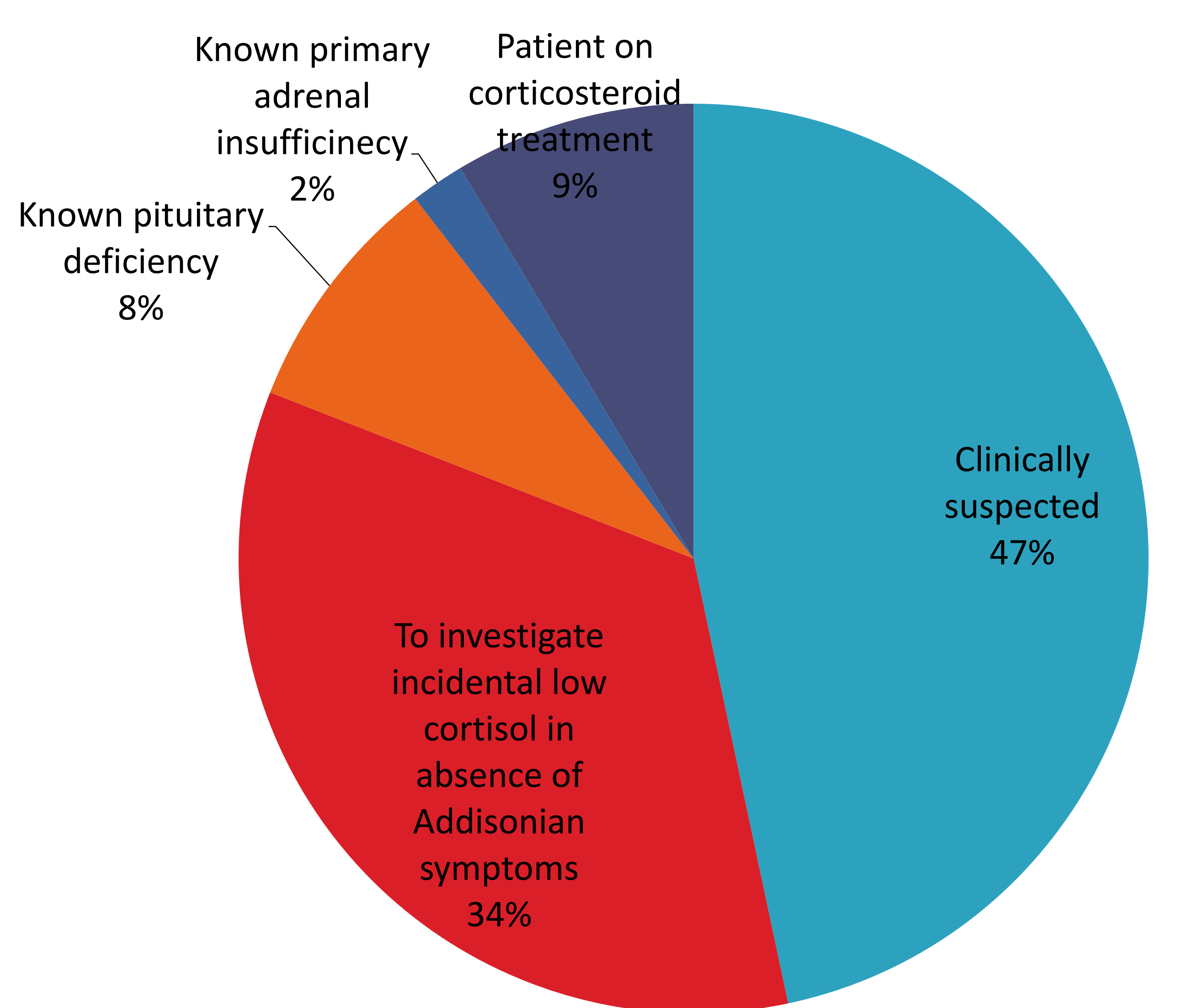

INPATIENTS:

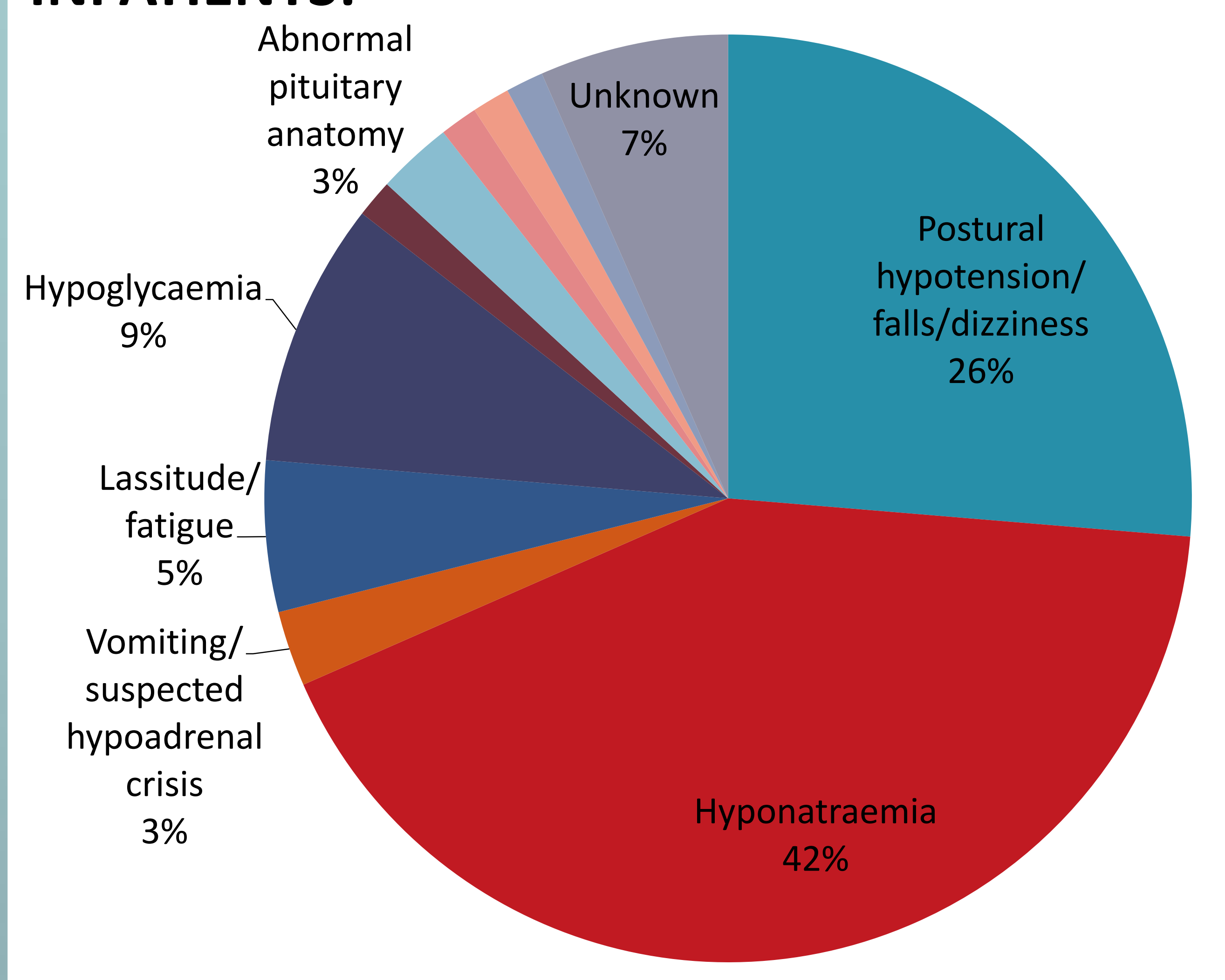

\section{Previous cortisol} OUTPATIENTS:

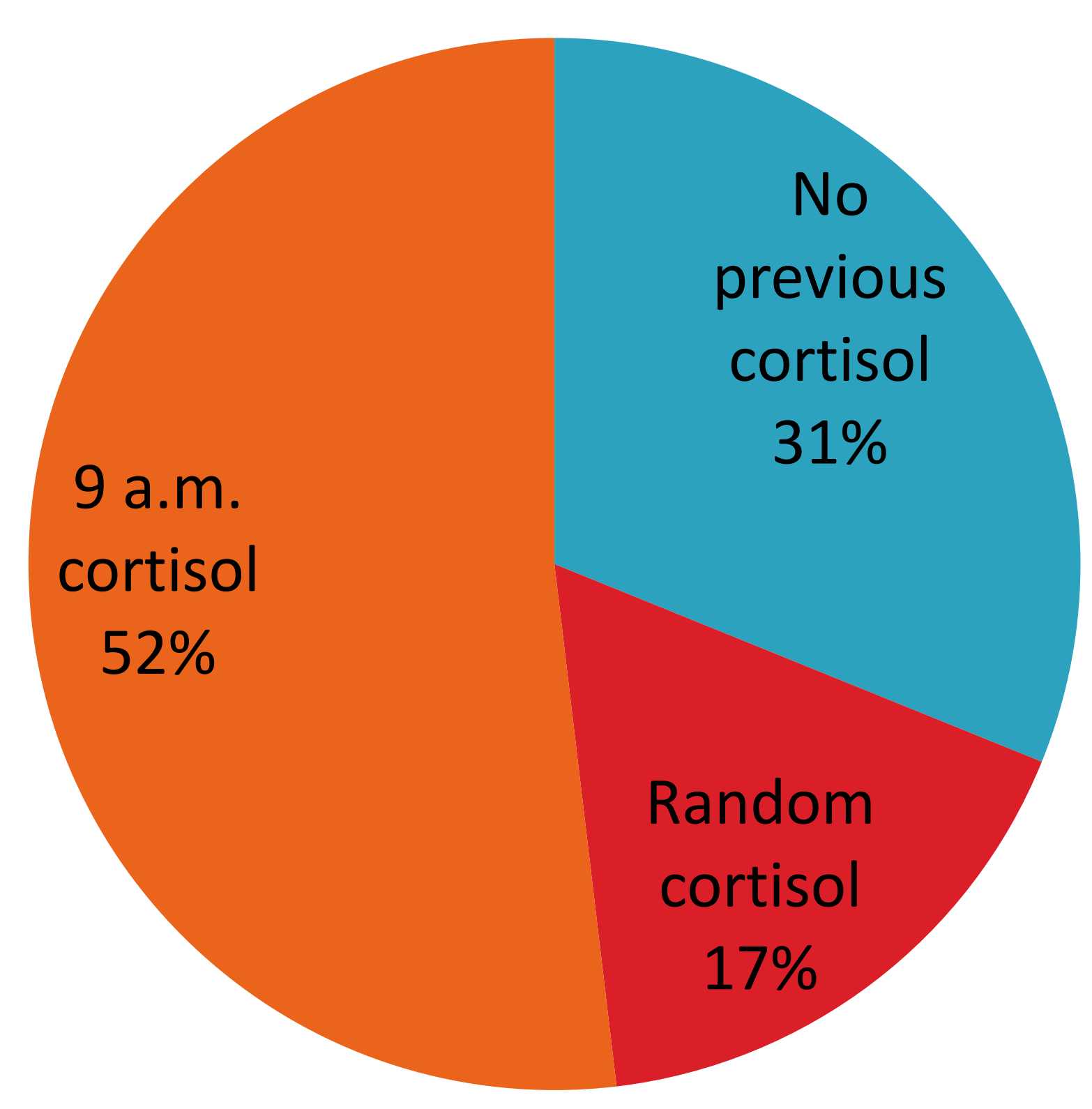

Spread of previous 9am cortisol (when measured)

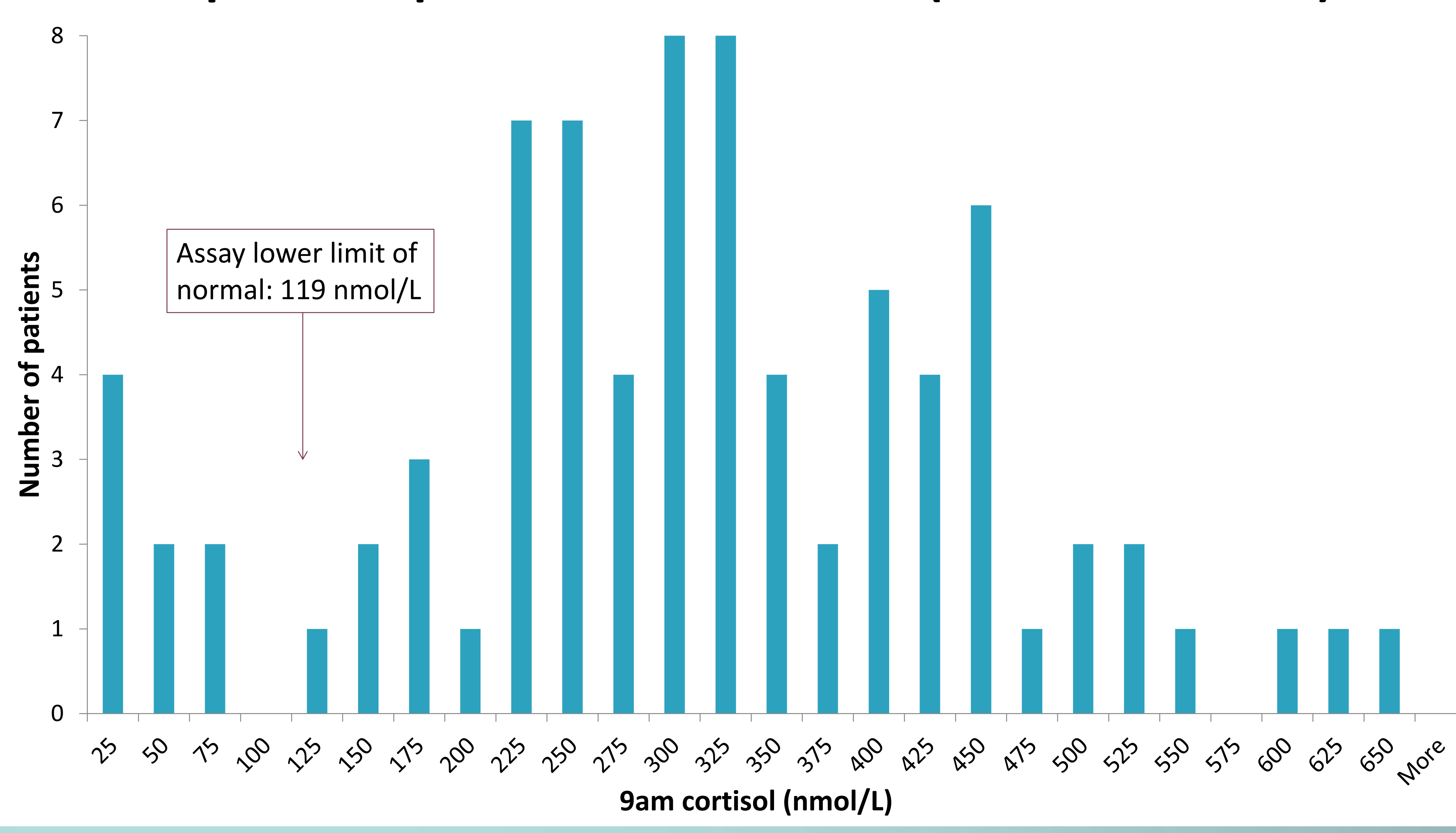

\section{SUMMARY FINDINGS}

- 9am cortisol was not consistently being measured prior to SST.

- When previous 9am cortisol was measured, median level was $297 \mathrm{nmol} / \mathrm{L}$, meaning a normal SST could be predicted with high certainty in many of these patients.

- All but one of the inpatient SST's that were performed to investigate hyponatraemia, hypotension, falls or apparent hypoglycaemia were interpreted as normal.

- All of the outpatient SST's performed to "exclude" Addison's were interpreted as normal.

- $9 \%$ of 9am cortisol measurements were less than $70 \mathrm{nmol} / \mathrm{L}$, in which case an abnormal SST would be a high certainty.

\section{NEW TRUST-WIDE MEASURE TO REDUCE INPATIENT SST'S:}

Pharmacy will now only issue tetracosactide if a previous 9am cortisol is measured. If the cortisol is higher than $300 \mathrm{nnol} / \mathrm{L}$, tetracosactide will be issued only if instructed by a member of the Endocrine department.

\section{CONCLUSIONS}

- Significant cost savings could be made by always measuring a 9am cortisol before proceeding to a SST.

- The 9am cortisol result should be interpreted in view of the low pre-test probability of hypoadrenalism in most patients undergoing SST's.

- SST might not be needed when a very low 9am cortisol is diagnostic. 